\title{
Extinction as a function of run structure in two choice human learning'
}

JOHN EDWARD HUNTER, Michigan State University, East Lansing, Mich. 48823

For 148 trials, human Ss predicted which of two stimulus lights would occur. During the first 112 trials each light occurred 56 times. For one group the light-sequence run structure consisted almost entirely of runs of Length 1 or 2 . For a second group the run lengths were uniformly distributed from 1 to 7. Only the left light occurred during the last 36 trials. The proportion of Ss who predicted "right" on the extinction trials was initially low for the long run group, this group extinguished slowly. The short run group started higher but dropped to zero rapidly.

In probability learning, the anomaly referred to as the Humphreys phenomenon is that the greater the rate of reinforcement during acquisition, the more rapid the extinction.

Most attempts to explain this phenomenon have been variants of the "discrimination hypotheses." These explanations capitalize on the fact that the greater the probability of $A_{1}$, the smaller the number of $A_{0}$ 's presented during acquisition. Theorists then note that the smaller the number of $A_{0}$ 's during acquisition, the greater the perceptual difference between acquisition and extinction. This explanation is clouded, however, by the fact that extinction is much more rapid following simple alternation of $A_{0}$ and $A_{1}$ than it is following the aperiodic sequences generated by a table of random numbers with the same proportion of $A_{0}$ 's and $A_{1}$ 's (.50).

It is the author's contention that the discrimination hypothesis has failed because theorists have assumed that the stimulus to which the Ss are responding in any given trial is either the immediately preceding stimulus or a small block of immediately preceding stimuli. On the other hand, Restle (1960) among others has suggested that the stimuli to which Ss are responding are the runs in the sequence.

This hypothesis is of particular interest in the light of the extinction phenomenon under consideration. Thus, in the case of independent trials, if the probability of $A_{1}$ is $\pi$. the expected run length for runs of $A_{0}$ is $1 / \pi$. This means that we can restate the Humphreys result by saying that the rate of extinction is a decreasing function of the expected run length of $A_{0}$ 's during acquisition. This formulation is also consistent with the results of the simple alternation study referred to above.

The problem is that when the acquisition sequences are selected on the basis of independent trials, the distribution of run lengths and the rate of reinforcement are completely confounded. Thus a test of the run length hypothesis demands an experimental procedure whereby the distribution of run length and the rate of reinforcement can be varied independently.

One solution to this problem would be to construct sequences on the basis of run distributions rather than trial by trial probabilities. Thus, for example, if the stimulus sequences are constructed by alternately choosing $A_{0}$ and $A_{1}$ runs at random from the same distribution of run lengths, the result is a set of sequences with the marginal probability of an $A_{1}$ fixed at .50 while the expected run length for $A_{0}$ and $A_{1}$ runs is at the disposal of the E.

Two such sequences were constructed for this experiment: one in which the acquisition trials were characterized by very short runs of both $A_{0}$ and $A_{1}$, and one in which run lengths were uniformly distributed from 1 to 7 . Although the rate of reinforcement during acquisition was the same for both sequences (.50), highly differentiated extinction curves were expected. For the short run sequence, the proportion of Ss predicting $A_{1}$ was expected to be rather high for the initial extinction trials and to drop rapidly to zero over successive trials. For the long run sequence, the proportion of Ss predicting an $A_{1}$ was expected to be low initially, but to converge to zero much more slowly than the corresponding proportions for the short run sequence.

\section{SUBJECTS}

Subjects for this experiment were 50 undergraduates enrolled in introductory psychology at the University of Illinois.

\section{APPARATUS}

The experimental room contained 15 individual booths, all facing the front of the room. The walls of each booth were high enough so that $\mathbf{S}$ could not see what any other $\mathbf{S}$ was doing but low enough so that he could see the large board at the front of the room a few inches from the ceiling. This board, painted flat black, had mounted on it three lights arranged in a triangle. The top light (ready signal) was green, and the two bottom lights (stimulus lights) were orange.

An IBM 1710 Control System was used to control the ready light and the stimulus lights. The system also read and recorded the responses on each trial. The duration and sequence of the lights was determined from stored instructions supplied by E prior to each experimental session. To start each trial the Control System turned on the ready signal and began scanning its interrupt points which were connected to Ss' response switches. Only the first response after the onset of the ready signal was recorded for each $\mathrm{S}$. One second after all Ss had responded, the ready light was turned off and the

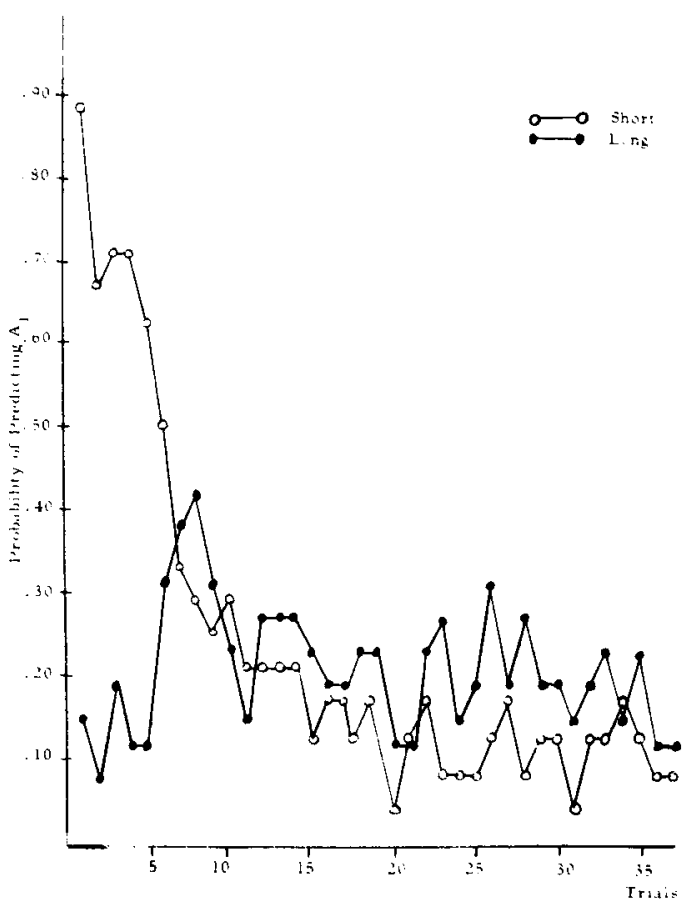

Fig. 1. Extinction probabilities. 
Table I

Extinction Probabilities (in Blocks of Nine Trials)

\begin{tabular}{|c|c|c|c|c|c|}
\hline Block & 1 & 2 & 3 & 4 & Means \\
\hline $\begin{array}{l}\text { Long Run } \\
\text { Sequence }\end{array}$ & .22 & .22 & .19 & .18 & .20 \\
\hline $\begin{array}{l}\text { Short Run } \\
\text { Sequence }\end{array}$ & .50 & .15 & .11 & .11 & .22 \\
\hline Means & .38 & .19 & .16 & .15 & \\
\hline
\end{tabular}

stimulus light for that trial was turned on for a duration of 2 sec. The interval between stimulus light and the onset of the ready light for the next trial was $1 \mathrm{sec}$. A piece of wood, $18 \times 4 \times 2$ in., painted black, was placed in each booth and used as a base on which to mount the response buttons. On each board a button was mounted 2 in. from each end on the centerline of the 4-in. surface. The response buttons actuated snap-action spring-return switches.

\section{PROCEDURE}

Subjects were assigned randomly to one of two stimulus sequences and were run in groups of seven to nine depending on how many Ss showed up for a given session. Twenty-four Ss were run on the short-run sequence, 26 on the long-run sequence. The instructions were paraphrased from Estes \& Straughn (1954).

\section{STIMULUS SEQUENCES}

Each of the stimulus sequences will be described by giving a list of numbers. Each number in the list represents the length of a run of lights on the same side. If the number is underlined, it means a run of right (coded $A_{1}$ for all Ss) lights; if the number is not underlined, it means a run of left (coded $\mathrm{A}_{0}$ ) lights.

Short run sequence: $1,1,1,4,1,2,3,1,1,1,2,2,2,2,1$, $1,1,1,3,1,1,1,1, \underline{3}, 4, \underline{3}, 2, \frac{1}{1}, 1,1,1,2,1,1,1,1,2,2,2$, $1,1,1,2,1,2,2,3,2,1,1,1,1,1,1,1,1,1,1,1,1,1,2,1$, $\underline{2}, 1, \underline{\dot{3}}, 2, \underline{1}, 2, \underline{1}, 1, \underline{1}, 1, \underline{1}, 1, \underline{1}, 36$

Long run sequence: $2, \underline{1}, 6, \underline{4}, 3, \underline{4}, 5, \underline{2}, 4, \underline{6}, 6, \underline{1}, 7, \underline{5}, 2$, $\underline{7}, 1, \underline{6}, 5, \underline{3}, 1, \underline{2}, 4, \underline{5}, 3, \underline{3}, 7, \underline{7}, 36$
Thus a short run sequence started LRLRRRRL ..., and the long run sequence started LLRLLLLLLRRRR ... .

For each sequence there were 112 "acquisition" trials and 36 "extinction" trials (the last run of 36 lefts being regarded as the extinction trials). At the end of acquisition, $\mathrm{Ss}$ in the short-sequence group had seen $25,9,3$, and 1 runs of Lengths $1,2,3$, and 4 , respectively, for both left and right. The long-run group had seen two runs of each length from 1 to 7 for both left and right.

RESULTS AND DISCUSSION

It was predicted that the group which had seen the short run sequence would start with a higher probability of predicting an $A_{1}$, but extinguish more rapidly than the group which had seen the long run sequences. Figure 1 displays the observed proportions of Ss predicting an $A_{1}$ on each of the 36 extinction trials for each of the two groups. The experimental hypothesis is confirmed.

For greater statistical stability (and to provide greater homogeneity of variance) mean proportions for blocks of nine trials are given in Table 1 . Here the prediction concerning the course of extinction is borne out more smoothly. In the analysis of variance for the extinction data the blocks effect with 3 deg of freedom had an F of 17.81 and the Blocks by Runs interaction with $3 \mathrm{deg}$ of freedom had an F of 14.20, both of which were significant at the .001 level.

\section{REFERENCES}

RESTLE, F. Psychology of choice and judgment. New York: Wiley, 1961.

\section{NOTE}

1. This paper is based on work submitted to the University of lllinois in partial fulfillment of the requirements for the Ph.D. degree. The author is particularly grateful to Dr. Raymond W. Frankmann, Mr. Scott Krueger, and Dr. Lawrence Stolurow for their kind assistance in this endeavor. The IBM 1710 Control System at the Training Research Laboratory of the University of Illinois was utilized in the execution of this study. This system is supported by funds from the Office of Naval Research (ONR), from the Advanced Research Projects Agency (ARPA), and from the National Defense Education Act (NDEA).

\section{(Continued from page 274)}

consistent with those of an earlier study (Battig, Brown, \& Schild, 1964) which used a transfer design to test the cluster hypothesis.

\section{REFERENCES}

BATTIG, W. F., BROWN, S. C., \& SCHILD, M. E. Serial position and sequential associations in serial learning. Journal of Experimental Psychology, 1964, 67, 449-457.
HESLIP, J. R., \& EPSTEIN, W. Effectiveness of serial position and preceding-item cues in serial learning. Journal of Experimental Psy chology, in press.

HOROWITZ, L. M., \& IZAWA, C. Comparison of serial and paired-associate learning. Journal of Experimental Psychology, 1963, $65,352-361$.

JOHNSON, R. C. Meaningfulness of eighty English words. Psychological Reports, 1961, 9,431.

YOUNG, R. K., HAKES, D. T., \& HICKS, R. Y. Ordinal position number as a cue in serial learning. Journal of Experimental Psychology, 1967, $73,427-438$ 